\title{
Neutrophil-to-lymphocyte ratio as a predictive or prognostic factor for gastric cancer treated with nivolumab: a multicenter retrospective study
}

\author{
Takatsugu Ogata ${ }^{1}$, Hironaga Satake ${ }^{2}$, Misato Ogata ${ }^{1}$, Yukimasa Hatachi $^{1}$, Kentaro \\ Inoue $^{3}$, Madoka Hamada ${ }^{3}$ and Hisateru Yasui ${ }^{1}$ \\ ${ }^{1}$ Department of Medical Oncology, Kobe City Medical Center General Hospital, Chuo-ku, Kobe City, Hyogo, 650-0047, Japan \\ ${ }^{2}$ Cancer Treatment Center, Kansai Medical University Hospital, Shinmachi, Hirakata City, Osaka, 573-1191, Japan \\ ${ }^{3}$ Department of Surgery, Kansai Medical University Hospital, Shinmachi, Hirakata City, Osaka, 573-1191, Japan \\ Correspondence to: Hironaga Satake, email: takeh1977@gmail.com \\ Keywords: advanced gastric cancer; nivolumab; neutrophil-to-lymphocyte ratio; predictive factors; prognostic factors \\ Received: May 28, $2018 \quad$ Accepted: September 08, $2018 \quad$ Published: October 02, 2018 \\ Copyright: Ogata et al. This is an open-access article distributed under the terms of the Creative Commons Attribution License \\ 3.0 (CC BY 3.0), which permits unrestricted use, distribution, and reproduction in any medium, provided the original author and \\ source are credited.
}

\section{ABSTRACT}

Introduction: The neutrophil-to-lymphocyte ratio (NLR) is effective as a predictive factor for lung cancer treated with nivolumab. The objective of this study was to determine the effectiveness of NLR for patients with advanced gastric cancer (AGC) treated with nivolumab.

Methods: This was a multicenter, retrospective study of patients with AGC treated with nivolumab from June 2017 to December 2017. The NLRs were calculated before the first cycle $\left(N_{L} R_{\text {pre }}\right)$ and two weeks after the first administration $\left(N L R_{\text {post }}\right)$.

Results: Twenty-six patients were enrolled (males 19, females 7 ) with a median age of 64 years. The overall response rate was $15 \%$. The median PFS was 80 days (range, $11-265$ ) and the median OS was 290 days (range, 21 - 332). Stratified with high NLR ( $\geq 5)$ and low NLR $(<5)$, the median PFS was shorter in the high NLR $_{\text {pre }}$ arm ( 87 vs. 45 days; $p=0.066$ ) and significantly shorter in the high $N_{\text {post }}$ arm (94 vs. 28 days; $p=0.014)$. The median OS was significantly shorter in the high $\mathbf{N L R}_{\text {pre }}$ arm ( 290 vs. 175 days; $p=0.008$ ) and in the high $N L R_{\text {post }}$ arm ( 290 vs. 69 days; $p<0.001$ ).

Conclusion: NLR may be an effective prognostic factor in patients with AGC treated with nivolumab.

\section{INTRODUCTION}

Immune checkpoint inhibitors are now widely used for many kinds of tumors. In 2017, the ATTRACTION-2 study [1] showed that nivolumab monotherapy was more effective for the pretreatment patients with advanced gastric cancer (AGC) than a placebo, and that it can be used in clinical practice for treatment [2]. However, in approximately $50 \%$ of patients, nivolumab was effective, and in only $10 \%$ of patients, nivolumab remained effective for more than a year according to the ATTRACTION-2 study [1]. In light of the more favorable responses observed in patients treated with nivolumab, many studies have focused on identifying predictive factors for favorable nivolumab responses. For example, programmed death ligand-1 (PD-L1) or programmed death ligand-2 (PD-L2), mutation burden, and mismatch repair deficiency (dMMR), have been investigated in many studies in terms of their association with nivolumab [3-6]. However, measuring these factors is not easy and can be time consuming. The pretreatment neutrophil-to-lymphocyte ratio (NLR), a marker of systemic inflammation, was recently shown to be associated with outcomes in a variety of cancers $[3,4]$. Some studies have reported that NLR is an effective prognostic and predictive factor. In patients with gastric cancer, Tanaka et al. reported that NLR at the 


\begin{tabular}{lcc}
\hline & $\mathbf{N}=\mathbf{2 6}$ & $\mathbf{( \% )}$ \\
\hline Gender, male/female & $19 / 7$ & $(73 / 27)$ \\
Age, median (range) & 64 & $(44-86)$ \\
ECOG PS, 0/1/2 & $2 / 22 / 2$ & $(8 / 85 / 8)$ \\
Location, Upper/Middle/Lower & $9 / 9 / 8$ & $(35 / 35 / 31)$ \\
Lauren classification, Intestinal/Diffuse & $14 / 13$ & $(52 / 48)$ \\
HER2 status, +/- & $3 / 23$ & $(12 / 89)$ \\
Number of previous treatments, $1 / 2 / \geq 3$ & $3 / 11 / 12$ & $(12 / 42 / 46)$ \\
Previous radiotherapy, $+/-$ & $3 / 23$ & $(12 / 89)$ \\
Liver metastasis & & $(27 / 73)$ \\
$\quad$ Yes/No & $7 / 19$ & $(54 / 46)$ \\
Ascites & & $(0.94-17.4)$ \\
$\quad$ Yes/No & $14 / 12$ & $(77 / 23)$ \\
Pretreatment NLR, median (range) & 2.22 & $(1.03-12.3)$ \\
Pretreatment NLR, $<5 / \geq 5$ & $20 / 6$ & $(81 / 19)$ \\
Posttreatment NLR, median (range) & 2.84 & $21 / 5$ \\
Posttreatment NLR, $<5 / \geq 5$ & &
\end{tabular}

Abbreviations: ECOG PS, the Eastern Cooperative Oncology Group Performance Status; NLR, neutrophil-to-lymphocyte ratio.

time of diagnosis reflects the progression of metastasis [5], and Min et al. reported that the postoperative NLR was associated with patient survival [6]. In patients with lung cancer treated with nivolumab, NLR was also associated with progression free survival (PFS) or overall survival (OS) [7, 8]. Kiriu et al. reported that NLR at 2 weeks after the first administration of nivolumab was associated with time to treatment failure [9]. However, the effectiveness of NLR as a prognosticator among patients with AGC treated with nivolumab is unknown. The objective of this study was to determine the effectiveness of NLR for AGC treated with nivolumab monotherapy.

\section{RESULTS}

\section{Patient characteristics}

Twenty-six patients were treated with nivolumab for AGC. Patient characteristics are summarized in Table 1. The median age at the time of treatment was 64 years (range, $44-86$; interquartile range [IQR], $59-71$ ), and $73 \%$ of the patients were male. The median pretreatment NLR $\left(\mathrm{NLR}_{\text {pre }}\right.$ ) was 2.22 (range, 0.94 - 17.4; IQR, 1.52 4.57), with the $\mathrm{NLR}_{\mathrm{pre}}<5$ in 20 patients $(77 \%)$ and $\mathrm{NLR}_{\mathrm{pre}}$ $\geq 5$ in 6 patients $(23 \%)$. The median posttreatment NLR $\left(\mathrm{NLR}_{\text {post }}\right.$ ) was 2.84 (range, $1.03-12.3$; IQR, 1.98-3.81), with $\mathrm{NLR}_{\text {post }}<5$ in 21 patients $(81 \%)$ and $\mathrm{NLR}_{\text {post }} \geq 5$ in 5 patients $(19 \%)$.

\section{Response to the treatment}

The overall response rate was $15 \%$ (4 of 26 patients), and the overall disease control rate was $42 \%$ (11 of 26 patients). When stratified according to high NLR $(\geq 5)$ and low NLR $(<5)$ values, the response rates were not significantly different (Table 2 ).

\section{Progression free survival and overall survival}

With a median follow up of 171 days, the median PFS was 76 days and the median OS was 290 days in the total population. The median PFS tended to be shorter in the high NLR arm $_{\text {(8) }}$ ardays vs. 45 days; hazard ratio [HR] 2.43; 95\% confidence interval [CI]: $0.92-6.42$; $\mathrm{p}=0.064)$ and significantly shorter in the high $\mathrm{NLR}_{\text {post }}$ arm (94 days vs. 28 days; HR 3.49, 95\% CI: 1.19 - 10.3; $\mathrm{p}=0.015$ ) (Figure 1). The median OS was also significantly shorter in the high NLR pre arm (290 days vs. 175 days; HR 5.38, 95\% CI: $1.34-21.6 ; \mathrm{p}=0.008$ ) and in the high $\mathrm{NLR}_{\text {post }}$ arm (290 days vs. 69 days; HR 14.4, 95\% CI: 3.13 $-66.7 ; \mathrm{p}<0.001$ ) (Figure 2). The other factors were not associated with PFS and OS (Table 3).

\section{Immune-related adverse events}

Regarding immune-related adverse events, hypothyroidism occurred in 2 patients, elevated liver 
Table 2: NLR levels of response

\begin{tabular}{lllccc}
\hline & & CR & PR & SD & PD \\
\hline \multirow{2}{*}{ NLR $_{\text {pre }}$} & high & 0 & 0 & 1 & 5 \\
& low & 1 & 3 & 6 & 10 \\
NLR $_{\text {post }}$ & high & 0 & 0 & 0 & 5 \\
\hline
\end{tabular}

Abbreviations: CR, complete response; PR, partial response; SD, stable disease; PD, progressive disease.

enzyme levels in 2 patients (grades 1 and 3 ), and vitiligo in 1 patient. One patient with grade 3 elevated liver enzyme level discontinued treatment. The four patients with hypothyroidism, elevated liver enzyme levels, and vitiligo continued receiving treatment after the occurrence of immune-related adverse events.

\section{DISCUSSION}

We observed that NLR, especially NLR ${ }_{\text {post}}$, was associated with PFS and OS. Our results indicated that the NLR might be useful as a prognostic factor of treatment with nivolumab monotherapy for AGC. This is the first report to show an association between NLR and clinical outcomes including PFS and OS for advanced gastric cancer patients treated with nivolumab.

We evaluated tumor responses and progressive disease according to RECIST and we considered the change in treatment. However, the activities of immune checkpoint inhibitors (ICIs), are different from cytotoxic agents, and pseudoprogression and hyperprogressive disease have been reported in patients treated with ICIs. In gastric cancer, hyperprogressive disease has been previously reported [10]. When the pseudoprogression occurred, we considered a change in treatment according to RECIST because we could not decide whether the progression was pseudoprogression or hyperprogressive disease. Recently, iRECIST was advocated [11], and "beyond progression" has been increasingly considered in tumor progression in treatment with ICIs. According to iRECIST, pseudoprogression may be noticed, but in the case of hyperprogressive disease the treatment is often continued inadequately. However, from the results of this study, it might be necessary to consider changing drugs as soon as progression is noted, when the NLR is high.

For the PFS and OS, the high $\mathrm{NLR}_{\text {pre }}$ tended to be short. Since nivolumab monotherapy for AGC is considered the salvage line, nivolumab monotherapy will be selected as the third line in many cases even if the NLR $_{\text {pre }}$ is high. The hazard ratios of PFS and OS in NLR were higher, which was thought to have greater effects on PFS and OS. Therefore, it is better to consider changing the regimen before progression, when $\mathrm{NLR}_{\text {post }}$ exceeds the threshold of 5 and they were treated with nivolumab; therefore, the study of Jung et al. [12] and the study of NSCLC [7-9] that included treatment with nivolumab were referred to for the NLR cut-off value (Table 4). Nivolumab was different from the other cytotoxic agents, so nivolumab monotherapy for NSCLC was used as the reference. It is necessary to discuss whether this cut-off value is valid or not, but it was suggested that NLR could predict survival.

The mechanism underlying the association of $\mathrm{NLR}_{\text {post }}$ with PFS or OS is not clearly understood. We hypothesized the influence of interleukin (IL)-17. It has been reported that IL-17 release the substance that mediates the migration of neutrophils [13]. In addition, IL$17 \mathrm{~A}$ has been reported to be involved in the mechanisms of resistance to immune checkpoint inhibitors [14]. In the case of high NLR ${ }_{\text {post }}$, the NLR was elevated because IL-17 levels had not decreased after the first dose of nivolumab.

\section{The biomarkers of immune checkpoint inhibitors}

In many studies regarding ICIs, biomarkers have been investigated. The expression of PD-L1 or PD-L2 [15], mutation burden [16], dMMR [17] are said to be associated with the efficacy of ICIs. Furthermore, the expressions of PD-L1 and PD-L2 are associated with the response to ICIs [15]. In patients with lung cancer, pembrolizumab was more effective for higher expression of PD-L1 [18]. However, in patients with gastric cancer, the rate of positivity for PD-L1 (>1\%) was only $17.3 \%$ [15]. When somatic mutation burdens of melanoma and non-small cell lung cancer were high [19], then the efficacy of ICIs was very high [16]. On the other hand, mutation burdens of gastric cancer were not very high [19]. The dMMR is reported to be a predictive factor of ICIs, and has been identified in $27 \%$ of patients with gastric cancer [20]. Identification of these biomarkers involved the use of archival specimen, and so did not reflect the current status, especially the third line. However, the NLR is easily identified at the time of drawing blood and dynamic changes can also be identified. 

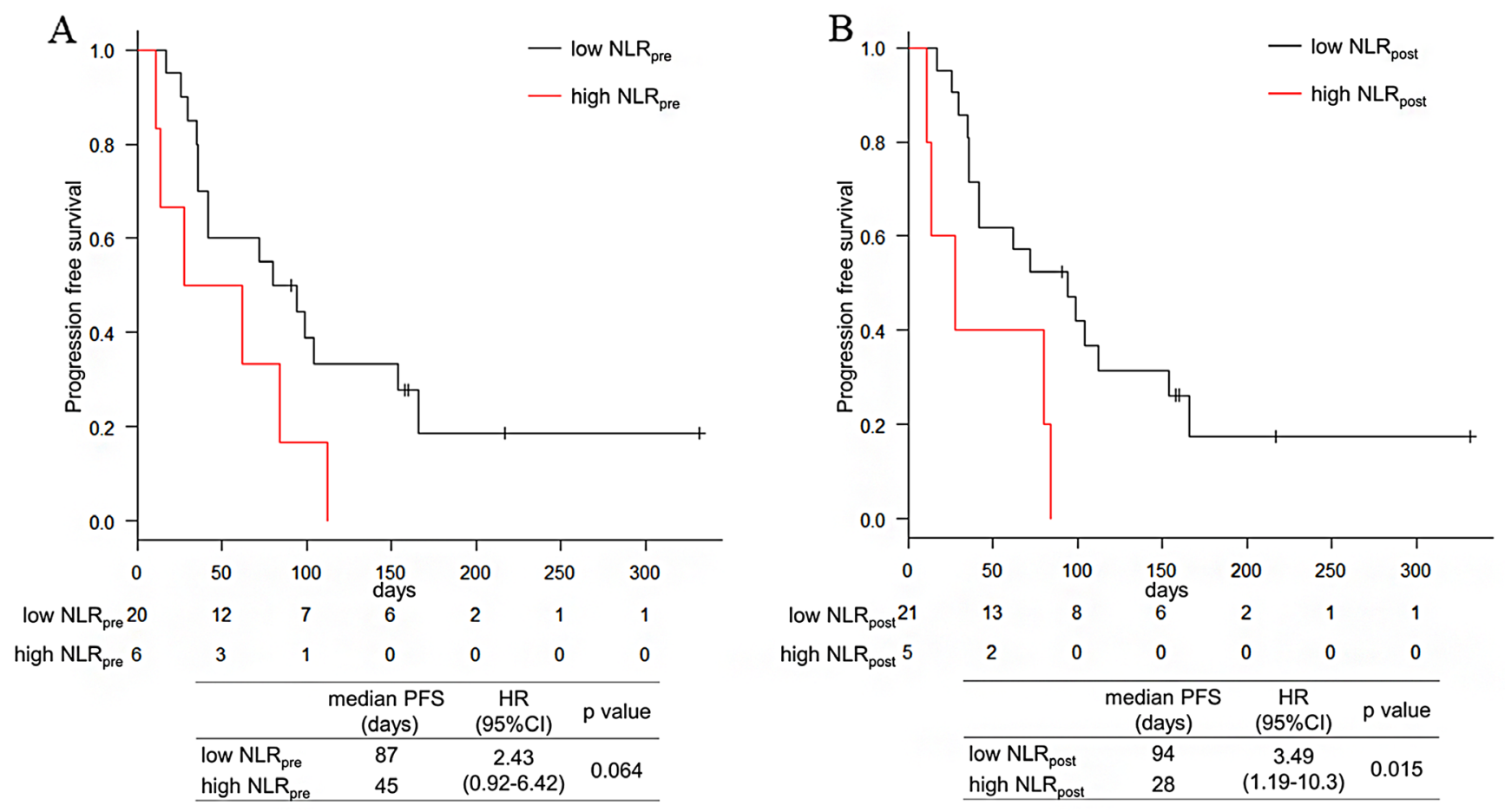

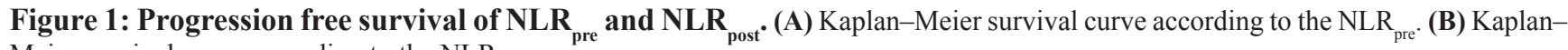
Meier survival curve according to the NLR post $^{\text {. }}$
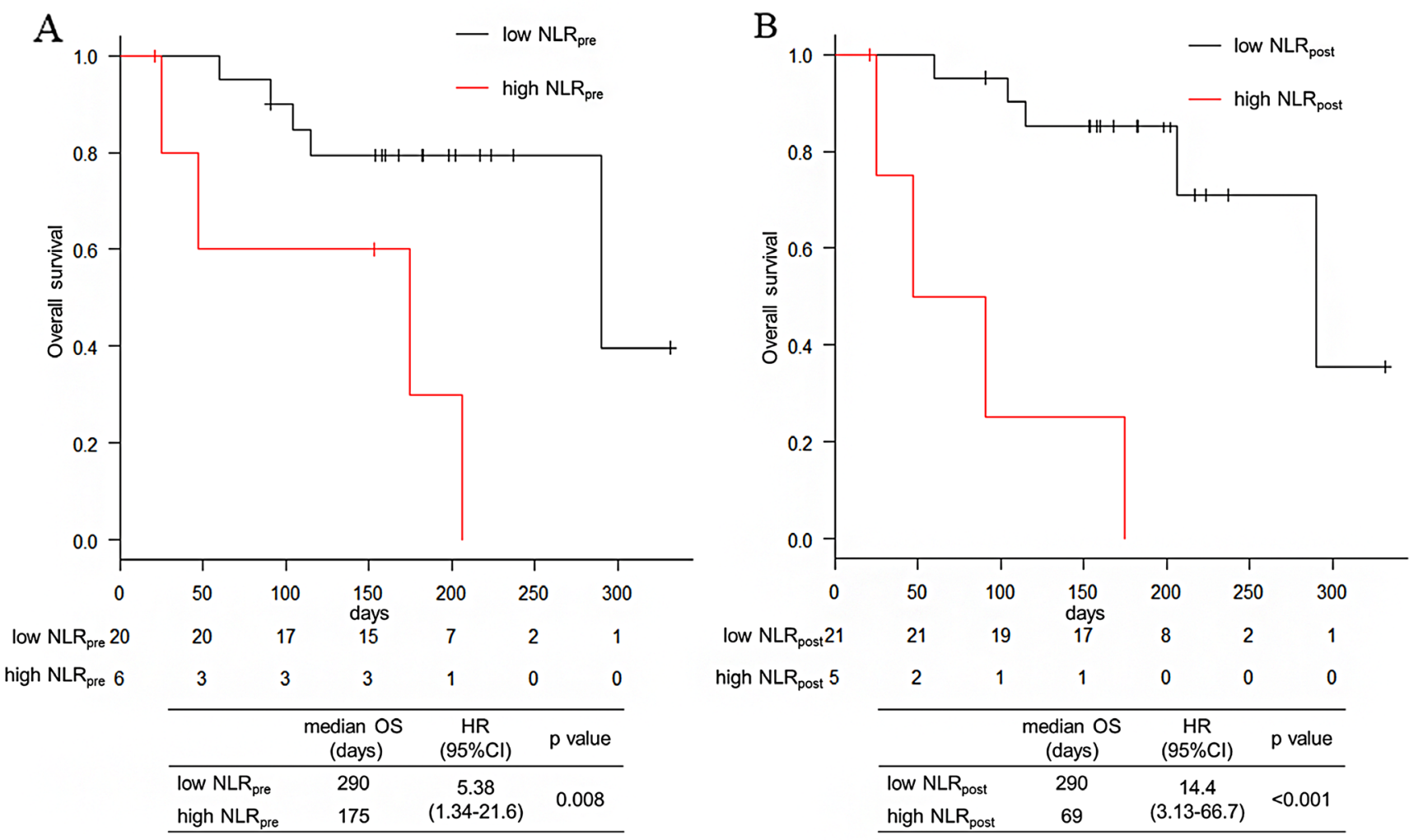

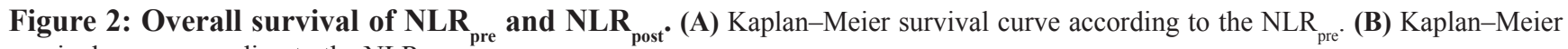
survival curve according to the $\mathrm{NLR}_{\text {post }}$. 
Table 3: Univariable analyses for progression free survival (PFS) and overall survival (OS)

\begin{tabular}{|c|c|c|c|c|}
\hline \multicolumn{5}{|l|}{ PFS: } \\
\hline & & HR & $95 \% \mathrm{CI}$ & p value \\
\hline Gender & Male/Female & 1.66 & $0.60-4.63$ & 0.322 \\
\hline Age & $\geq 65 /<65$ & 0.638 & $0.26-1.55$ & 0.314 \\
\hline ECOG PS & $0 / 1 / 2$ & 2.20 & $0.80-6.04$ & 0.251 \\
\hline \multirow{2}{*}{ Tumor location } & $\mathrm{U} / \mathrm{L}$ & 1.84 & $0.58-5.85$ & 0.302 \\
\hline & $\mathrm{M} / \mathrm{L}$ & 2.79 & $0.88-8.83$ & 0.303 \\
\hline Lauren classification & Intestinal/Diffuse & 1.25 & $0.53-2.95$ & 0.603 \\
\hline HER2 & $+/-$ & 2.46 & $0.71-8.59$ & 0.142 \\
\hline Liver metastasis & $+/-$ & 0.84 & $0.32-2.22$ & 0.724 \\
\hline Ascites & $+/-$ & 1.04 & $0.44-2.48$ & 0.926 \\
\hline Pretreatment NLR & $\geq 5 /<5$ & 2.43 & $0.92-6.42$ & 0.064 \\
\hline Posttreatment NLR & $\geq 5 /<5$ & 3.49 & $1.19-10.3$ & 0.015 \\
\hline \multicolumn{5}{|l|}{ OS: } \\
\hline & & HR & $95 \% \mathrm{CI}$ & $p$ value \\
\hline Gender & Male/Female & 2.23 & $0.45-11.0$ & 0.310 \\
\hline Age & $\geq 65 /<65$ & 1.47 & $0.39-5.57$ & 0.565 \\
\hline ECOG PS & $0 / 1 / 2$ & 4.05 & $0.87-18.8$ & 0.172 \\
\hline \multirow{2}{*}{ Tumor location } & $\mathrm{U} / \mathrm{L}$ & 2.33 & $0.24-23.1$ & 0.469 \\
\hline & $\mathrm{M} / \mathrm{L}$ & 3.51 & $0.40-30.5$ & 0.256 \\
\hline Lauren classification & Intestinal/Diffuse & 1.23 & $0.29-5.16$ & 0.779 \\
\hline HER2 & $+/-$ & - & - & - \\
\hline Liver metastasis & $+/-$ & - & - & - \\
\hline Ascites & $+/-$ & 1.54 & $0.38-6.20$ & 0.538 \\
\hline Pretreatment NLR & $\geq 5 /<5$ & 5.38 & $1.34-21.6$ & 0.008 \\
\hline Posttreatment NLR & $\geq 5 /<5$ & 14.4 & $3.13-66.7$ & $<0.001$ \\
\hline
\end{tabular}

Abbreviations: ECOG PS, the Eastern Cooperative Oncology Group Performance Status; U, Upper; M, Middle; L, Lower.

\section{The limitation of this study}

The limitations of this study include its retrospective design, the small cohort size, and the relatively short follow up period. However, the overall response rate was $12 \%$ and the disease control rate was $42 \%$. These results were similar to those of the ATTRACTION-2 study [1], which is one reason why our study was valid regardless of the retrospective design that included only two centers. However, because of the relatively small cohort size, a multivariate analysis was not possible. It is, therefore, necessary to perform a similar larger analysis using a prospective design to confirm the results. The follow up period of this study was relatively short, and therefore we will continue to follow the patients and report the updated data.

In conclusion, NLR, especially posttreatment NLR, may be effective as a prognostic factor in patients with gastric cancer treated with nivolumab monotherapy. Further studies are warranted to investigate how NLR can be used to detect disease progression as early as possible. 
Table 4: Studies of the baseline NLR for AGC treated with chemotherapy

a) Studies on the efficacy of NLR for evaluating AGC

\begin{tabular}{lccccc}
\hline Treatment & Patients & Cut-off & Line & Outcome & Reference \\
\hline RAM \pm PTX & 265 & 5 & $2^{\text {nd }}$ & PFS, OS & {$[12]$} \\
Chemotherapy & 104 & 3 & $1^{\text {st }}$ & OS & {$[21]$} \\
Chemotherapy & 268 & 3 & $1^{\text {st }}$ & OS & {$[22]$} \\
S- + CDDP & 110 & 3 & $1^{\text {st }}$ & OS & {$[23]$} \\
Chemotherapy & 868 & 2.7 & $2^{\text {nd }}$ & OS & {$[24]$} \\
Chemotherapy & 143 & 3.34 & $1^{\text {st }}$ & PFS, OS & {$[25]$} \\
\hline b) Studies of the efficacy of the NLR for NSCLC treated with nivolumab & & Outcome & Reference \\
\hline \multicolumn{7}{c}{ Patients } & Cut-off & Line & OS & {$[7]$} \\
\hline & 175 & 5 & $2^{\text {nd }}-$ & OS & {$[9]$} \\
\end{tabular}

Abbreviations: PFS, progression free survival; OS, overall survival; RAM, ramucirumab; PTX, paclitaxel; CDDP, cisplatin.

\section{MATERIALS AND METHODS}

\section{Patients and treatments}

We performed a retrospective study based on the medical records of patients at two centers, Kobe City Medical Center General Hospital and Kansai Medical University Hospital. The patients with gastric cancer were histologically diagnosed with adenocarcinoma, and they all had experienced either recurrence after surgery or developed de novo Stage IV cancer. Patients included in the study were treated with nivolumab monotherapy. The data collected included the following: gender, age, Eastern Cooperative Oncology Group Performance Status (ECOG PS), tumor location, HER2 status, prior treatment histories at the time of the first administration of nivolumab, the history of radiotherapy, the location of metastasis, NLR ${ }_{\text {pre }}$, and NLR ${ }_{\text {post }}$. Nivolumab was administered intravenously at dose of $3 \mathrm{mg} / \mathrm{kg}$ as one cycle every two weeks.

This retrospective analysis was approved by the Institutional Review Board of Kobe City Medical Center General Hospital and Kansai Medical University Hospital.

\section{Neutrophil-to-lymphocyte ratio}

We recorded absolute neutrophil count (ANC) and absolute lymphocyte count (ALC) on the day of the first administration and also two weeks after this. The NLR was defined as ANC divided by ALC. The NLR pre was defined as the NLR at the time of the first administration, and NLR ${ }_{\text {post }}$ was defined as the NLR at two weeks after the first administration of nivolumab.
A previous study found that a baseline $\mathrm{NLR}<5$, which is commonly used as an NLR threshold, was associated with an improved survival in lung cancer patients treated with nivolumab [7], and in gastric cancer patients treated with paclitaxel and ramucirumab therapy [12]. We, therefore, used 5 as the NLR cut-off value in this study.

\section{Statistical analysis}

OS was defined as the time from the date of first administration of nivolumab to the date of death due to any cause. Patients who were still alive were censored at the last follow-up. PFS was defined as the time from the date of first administration of nivolumab until disease progression. The OS and PFS curves were estimated using the Kaplan-Meier method and compared using the logrank test. $\mathrm{P}<0.05$ was considered statistically significant in all analyses. The analysis was performed using $\mathrm{R}$ (The R Development Core Team, Vienna, Austria).

\section{Abbreviations}

AGC, advanced gastric cancer; ALC, absolute lymphocyte count; ANC, absolute neutrophil count; CI, confidence interval; dMMR, mismatch repair deficiency; ECOG PS, Eastern Cooperative Oncology Group Performance Status; HR, hazard ratio; IQR, interquartile range; NLR, neutrophil-to-lymphocyte ratio; NLR posttreatment NLR; $\mathrm{NLR}_{\text {pre }}$, pretreatment NLR; OS, overall survival; PD-L1, programmed death ligand-1; PD-L2, programmed death ligand-2; PFS, progression free survival. 


\section{Author contributions}

Takatsugu Ogata: Substantial contributions to the conception of the work and drafting the work or revising it critically for important intellectual content.

Hironaga Satake: Substantial contributions to the conception of the work and agreement to be accountable for all aspects of the work.

Misato Ogata: The acquisition of data for the work.

Yukimasa Hatachi: The acquisition of data for the work.

Kentaro Inoue: The acquisition of data for the work.

Madoka Hamada: The analysis and interpretation of data for the work.

Hisateru Yasui: Final approval of the version to be published.

\section{Ethics approval and consent to participate}

All procedures followed were in accordance with the ethical standards of the responsible committee on human experimentation (institutional and national) and with the Helsinki Declaration of 1964 and later versions. Informed consent to be included in the study, or the equivalent, was obtained from all patients.

\section{CONFLICTS OF INTEREST}

None.

\section{FUNDING}

Not applicable.

\section{REFERENCES}

1. Kang YK, Boku N, Satoh T, Ryu MH, Chao Y, Kato K, Chung HC, Chen JS, Muro K, Kang WK, Yeh KH, Yoshikawa $\mathrm{T}$, Oh $\mathrm{SC}$, et al. Nivolumab in patients with advanced gastric or gastro-oesophageal junction cancer refractory to, or intolerant of, at least two previous chemotherapy regimens (ONO-4538-12, ATTRACTION-2): a randomised, double-blind, placebocontrolled, phase 3 trial. Lancet. 2017; 390: 2461-71. https://doi.org/10.1016/S0140-6736(17)31827-5.

2. Japanese Gastric Cancer Association (JGCA). Gastric Cancer Treatment Guidelines, 5th edition. Tokyo: Kanehara Inc. 2018.

3. Guthrie GJ, Charles KA, Roxburgh CS, Horgan PG, McMillan DC, Clarke SJ. The systemic inflammationbased neutrophil-lymphocyte ratio: experience in patients with cancer. Crit Rev Oncol Hematol. 2013; 88: 218-30. https://doi.org/10.1016/j.critrevonc.2013.03.010.

4. Templeton AJ, McNamara MG, Seruga B, Vera-Badillo FE, Aneja P, Ocana A, Leibowitz-Amit R, Sonpavde G, Knox JJ, Tran B, Tannock IF, Amir E. Prognostic role of neutrophil-to-lymphocyte ratio in solid tumors: a systematic review and meta-analysis. J Natl Cancer Inst. 2014; 106: dju124. https://doi.org/10.1093/jnci/dju124.

5. Tanaka H, Muguruma K, Toyokawa T, Kubo N, Ohira M, Hirakawa K. Differential impact of the neutrophillymphocyte ratio on the survival of patients with stage IV gastric cancer. Dig Surg. 2014; 31: 327-33. https://doi.org/10.1159/000369278.

6. Min KW, Kwon MJ, Kim DH, Son BK, Kim EK, Oh YH, Wi YC. Persistent elevation of postoperative neutrophil-to-lymphocyte ratio: a better predictor of survival in gastric cancer than elevated preoperative neutrophil-to-lymphocyte ratio. Sci Rep. 2017; 7: 13967. https://doi.org/10.1038/s41598-017-13969-x.

7. Bagley SJ, Kothari S, Aggarwal C, Bauml JM, Alley EW, Evans TL, Kosteva JA, Ciunci CA, Gabriel PE, Thompson JC, Stonehouse-Lee S, Sherry VE, Gilbert E, et al. Pretreatment neutrophil-to-lymphocyte ratio as a marker of outcomes in nivolumab-treated patients with advanced non-small-cell lung cancer. Lung Cancer. 2017; 106: 1-7. https://doi.org/10.1016/j.lungcan.2017.01.013.

8. Diem S, Schmid S, Krapf M, Flatz L, Born D, Jochum W, Templeton AJ, Fruh M. Neutrophil-toLymphocyte ratio (NLR) and Platelet-to-Lymphocyte ratio (PLR) as prognostic markers in patients with non-small cell lung cancer (NSCLC) treated with nivolumab. Lung Cancer. 2017; 111: 176-181. https://doi.org/10.1016/j.lungcan.2017.07.024.

9. Kiriu T, Yamamoto M, Nagano T, Hazama D, Sekiya R, Katsurada M, Tamura D, Tachihara M, Kobayashi K, Nishimura Y. The time-series behavior of neutrophil-tolymphocyte ratio is useful as a predictive marker in nonsmall cell lung cancer. PLoS One. 2018; 13: e0193018. https://doi.org/10.1371/journal.pone.0193018.

10. Ogata T, Satake H, Ogata M, Hatachi Y, Yasui H. Hyperprogressive disease in the irradiation field after a single dose of nivolumab for gastric cancer: a case report. Case Rep Oncol. 2018; 11: 143-50. https://doi.org/10.1159/000487477.

11. Seymour L, Bogaerts J, Perrone A, Ford R, Schwartz LH, Mandrekar S, Lin NU, Litiere S, Dancey J, Chen A, Hodi FS, Therasse P, Hoekstra OS, et al. iRECIST: guidelines for response criteria for use in trials testing immunotherapeutics. Lancet Oncol. 2017; 18: e143-52. https://doi.org/10.1016/S1470-2045(17)30074-8.

12. Jung M, Ryu MH, Oh DY, Kang M, Zang DY, Hwang IG, Lee KW, Kim KH, Shim BY, Song EK, Sym SJ, Han HS, Park YL, et al. Efficacy and tolerability of ramucirumab monotherapy or in combination with paclitaxel in gastric cancer patients from the Expanded Access Program Cohort by the Korean Cancer Study Group (KCSG). Gastric Cancer. 2018; 21:819-830. https://doi.org/10.1007/s10120-018-0806-1.

13. Motomura T, Shirabe K, Mano Y, Muto J, Toshima T, Umemoto Y, Fukuhara T, Uchiyama H, Ikegami T, 
Yoshizumi T, Soejima Y, Maehara Y. Neutrophillymphocyte ratio reflects hepatocellular carcinoma recurrence after liver transplantation via inflammatory microenvironment. J Hepatol. 2013; 58: 58-64. https://doi.org/10.1016/j.jhep.2012.08.017.

14. Akbay EA, Koyama S, Liu Y, Dries R, Bufe LE, Silkes M, Alam MM, Magee DM, Jones R, Jinushi M, Kulkarni M, Carretero J, Wang X, et al. Interleukin-17A Promotes Lung Tumor Progression through Neutrophil Attraction to Tumor Sites and Mediating Resistance to PD-1 Blockade. J Thorac Oncol. 2017; 12: 1268-79. https://doi.org/10.1016/j.jtho.2017.04.017.

15. Wang L, Zhang Q, Ni S, Tan C, Cai X, Huang D, Sheng W. Programmed death-ligand 1 expression in gastric cancer: correlation with mismatch repair deficiency and HER2-negative status. Cancer Med. 2018; 7: 2612-20. https://doi.org/10.1002/cam4.1502.

16. Takahashi M. [Genetic mutation accumulation and clinical outcome of immune checkpoint blockade therapy] [Article in Japanese]. Gan To Kagaku Ryoho. 2016; 43: 678-82.

17. Le DT, Uram JN, Wang H, Bartlett BR, Kemberling $\mathrm{H}$, Eyring AD, Skora AD, Luber BS, Azad NS, Laheru D, Biedrzycki B, Donehower RC, Zaheer A, et al. PD-1 blockade in tumors with mismatchrepair deficiency. N Engl J Med. 2015; 372: 2509-20. https://doi.org/10.1056/NEJMoa1500596.

18. Reck M, Rodriguez-Abreu D, Robinson AG, Hui R, Csőszi T, Fülöp A, Gottfried M, Peled N, Tafreshi A, Cuffe S, O'Brien M, Rao S, Hotta K, et al; KEYNOTE-024 Investigators. Pembrolizumab versus chemotherapy for PD-L1-positive nonsmall-cell lung cancer. N Engl J Med. 2016; 375: 1823-33. https://doi.org/10.1056/NEJMoa1606774.

19. Alexandrov LB, Nik-Zainal S, Wedge DC, Aparicio SA, Behjati S, Biankin AV, Bignell GR, Bolli N, Borg A, Borresen-Dale AL, Boyault S, Burkhardt B, Butler AP, et al. Signatures of mutational processes in human cancer. Nature. 2013; 500: 415-21. https://doi.org/10.1038/nature12477.
20. Pereira MA, Ramos MFK, Faraj SF, Dias AR, Yagi OK, Zilberstein B, Cecconello I, Alves VAF, de Mello ES, Ribeiro U Jr. Clinicopathological and prognostic features of Epstein-Barr virus infection, microsatellite instability, and PD-L1 expression in gastric cancer. J Surg Oncol. 2018; 117: 829-39. https://doi.org/10.1002/jso.25022.

21. Jeong JH, Lim SM, Yun JY, Rhee GW, Lim JY, Cho JY, Kim YR. Comparison of two inflammationbased prognostic scores in patients with unresectable advanced gastric cancer. Oncology. 2012; 83: 292-9. https://doi.org/10.1159/000342376.

22. Cho IR, Park JC, Park CH, Jo JH, Lee HJ, Kim S, Shim CN, Lee H, Shin SK, Lee SK, Lee YC. Pre-treatment neutrophil to lymphocyte ratio as a prognostic marker to predict chemotherapeutic response and survival outcomes in metastatic advanced gastric cancer. Gastric Cancer. 2014; 17: 703-10. https://doi.org/10.1007/s10120-013-0330-2.

23. Gonda K, Shibata M, Sato Y, Washio M, Takeshita H, Shigeta H, Ogura M, Oka S, Sakuramoto S. Elevated neutrophil-to-lymphocyte ratio is associated with nutritional impairment, immune suppression, resistance to S-1 plus cisplatin, and poor prognosis in patients with stage IV gastric cancer. Mol Clin Oncol. 2017; 7: 1073-8. https://doi.org/10.3892/mco.2017.1438.

24. Fanotto V, Cordio S, Pasquini G, Fontanella C, Rimassa L, Leone F, Rosati G, Santini D, Giampieri R, Di Donato S, Tomasello G, Silvestris N, Pietrantonio $\mathrm{F}$, et al. Prognostic factors in 868 advanced gastric cancer patients treated with second-line chemotherapy in the real world. Gastric Cancer. 2017; 20: 825-33. https://doi.org/10.1007/s10120-016-0681-6.

25. Musri FY, Mutlu H, Eryilmaz MK, Salim DK, Gunduz $\mathrm{S}$, Coskun HS. The neutrophil to lymphocyte ratio is an independent prognostic factor in patients with metastatic gastric cancer. Asian Pac J Cancer Prev. 2016; 17: 1309-12. 